\title{
Manifestações religiosas e a defesa dos direitos sociais e ambientais: um estudo de caso no município de Teixeiras -MG
}

\author{
Religious manifestations and the defense of social and environmental rights: A case \\ study in the municipality of Teixeiras - MG
}

\section{Geovanna Laura Santos Januárioº ${ }^{1}$ Edson Soares Fialho²}

RESUMO: A atividade econômica da mineração, não apenas gera impactos sobre os elementos físicos da natureza, mas também atingem a toda comunidade do entorno imediato, que na busca de se proteger, canalizam forças para a defesa do direito à terra e dos direitos sociais. Assim, a presente pesquisa busca demonstra como a religiosidade, junto aos movimentos sociais e ambientais, e suas influências no município de Teixeiras - MG, onde a implantação e atividade da ação da mineradora Zona da Mata Mineira - ZMM - estão em vigor, gerando diversos conflitos e divergências. Para isso, o procedimento utilizado para coleta de informações foi o método da observação participante, que consiste na participação do pesquisador nas atividades cotidianas relacionadas a uma área da vida social, a fim de estudar aspectos de vida da comunidade. Nesse sentido, acompanhando a dinâmica acerca do debate da mineração, elencamos três momentos, na qual delimitou-se para análise, que foram a primeira e segunda assembleia popular (27 de abril de 2019 e 7 de março de 2020) e os Festejos de Nossa Senhora Aparecida, na comunidade de São Pedro (26 de agosto de 2019), que foram por meio da observação de eventos em seus contextos naturais.

PALAVRAS-CHAVE: Conflito; Injustiça ambiental; Religião.

ABSTRACT: The economic activity of mining not only generates impacts on the physical elements of nature, but also affects the entire community of the immediate surroundings, which in the search to protect themselves, channel forces to defend the right to land and social rights. Thus, this research demonstrates how religiosity, together with social and environmental movements, and their influences in the municipality of Teixeiras - MG, where the implementation and activity of the mining company Zona da Mata Mineira - ZMM - are in force, generating various conflicts and differences. For this, the procedure used to collect information was the method of participant observation, which consists of the participation of the researcher in daily activities related to an area of social life, in order to study aspects of community life, In this sense, following the dynamics about the mining debate, We list three moments, in which it was delimited for analysis, which were the First and Second Popular Assembly (April 27, 2019 and March 7, 2020) and the Feasts of Our

\footnotetext{
1 Licenciada em Geografia da Universidade Federal de Viçosa. Bolsista de Iniciação Científica - CNPQ, UFV. Membro Laboratório de Biogeografia e Climatologia (Bioclima). E-mail: geovanna.januario@ufv.br.
}

2 Docente do Departamento de Geografia da Universidade Federal de Viçosa, Coordenador do Laboratório de Biogeografia e Climatologia (Bioclima). Professor do Programa de Pós-graduação em Geografia da Universidade Federal de Viçosa e Universidade Federal do Espírito Santo. E-mail: fialho@ufv.br

\section{AGRADECIMENTOS:}

Ao CNPq pela concessão da Bolsa de Iniciação científica para o desenvolvimento do projeto: Racismo Ambiental: uma análise de casos de comunidades étnicos discriminadas frente aos desastres ambientais, registrado na SISPPG como o número de projeto: 200784 e número de registro: 10705274580 e ao Laboratório de Biogeografia e Climatologia (Bioclima), lotado no Departamento de Geografia da UFV. 
Lady Aparecida, in the community of St. Peter (August 26, 2019), which were used through the observation of events in their natural contexts.

KEYWORDS: Conflit; Environmental injustice; Religion.

\section{INTRODUÇÃO}

A relação estabelecida entre o homem e a natureza e suas práticas se tornam o ponto principal dos estudos da Geografia (FIALHO, 2007), analisando, assim, as espacialidades e territorialidades dos mesmos, o cuidado do homem e seu empenho com a natureza, quando envolvem uma relação cultural.

Conforme Santos (2009), se tem um processo político e com técnicas, provocando uma socialização e relações dialéticas, a teologia, quando evidenciada, cria uma relação objetiva e subjetiva do homem com o espaço.

De acordo com Gil Filho (2004, p. 2), "a Geografia da Religião é uma subdisciplina da Geografia Humana que tem por objeto o fenômeno religioso visto como um espaço de relações objetivas e subjetivas consubstanciadas em formas simbólicas mediadas pela religião".

Os efeitos da relação religião $\mathrm{x}$ espaço são decorrentes da característica complexa pela qual se organiza o fenômeno religioso. O pressuposto de que a religião está impregnada de elementos míticos em sua dimensão espacial revela a saturação do sentir mítico; se a religião se diferencia do mito pela representatividade, o espaço no qual o Homem religioso se realiza também é representacional. (SILVA; GIL FILHO, p. 77, 2009).

A relação do homem com a natureza intermediada pela religiosidade, independentemente de sua origem, estabelece uma ressignificação de espaços por tratar a terra e seus elementos como objetos de análise. Essa relação cria ações geográficas, como a espacialização, territorialização cultural e construção social.

Um exemplo visível são os discursos de alguns segmentos dos sistemas religiosos, onde a natureza é objeto a se preservar por ser um meio sagrado cedido por forças maiores, e carrega consigo o fato da exploração da mesma para a sobrevivência no mundo. Conforme diz Silva e Gil Filho, todo esse processo de espacialização é dado pelo discurso fundador:

O primeiro passo da espacialização do fenômeno religioso é dado pelo discurso fundador, que transforma experiências religiosas e míticas em verdades religiosas. Trata-se de um discurso que é reestruturado pelo líder religioso que dirigidas aos enunciatários pode haver a eficácia simbólica necessária na espacialização e nominação da experiência religiosa com o mundo. (SILVA. GIL FILHO, p. 79, 2009). 
Partindo desse princípio, a Geografia com a Religião tem total proximidade e, quando analisada, conseguimos adquirir diversos discursos religiosos que geram consequências e influências nos movimentos de resistências frente a desastres e a injustiças ambientais:

A análise da Geografia da Religião apresenta duas linhas de pensamento: uma estritamente religiosa, onde a religião exerce uma influência sobre a percepção humana e tudo ao seu redor, focada no campo de ação teológico e da cosmologia. A outra se refere à religião propriamente dita, propondo a relação entre religião, sociedade, cultura e meio ambiente. (CLAVAL, 1992, p. 102).

Intitula-se Injustiça Ambiental quando algum grupo da sociedade desigual é injustiçado por pertencer a uma classe fora de uma ascensão, estando dentro de grupos de baixa renda, população de etnias discriminadas e populações periféricas. Nos discursos religiosos analisados neste artigo, o foco vai para esses grupos sociais e para a primeira perspectiva de Claval (1992), em que a religião influencia na percepção humana a ponto de gerar um movimento de resistências.

Assim, o presente estudo traz o histórico de desenvolvimento de algumas religiões e suas perspectivas ambientais, analisando como a vertente trata a relação homem versus natureza e como, a partir de lutas da religião e também dos movimentos sociais, esses se uniram para gerar uma luta em comum. Após esses apontamentos, a pesquisa trará uma análise dos movimentos religiosos de resistência da Zona da Mata Mineira, enfatizando casos da comunidade de São Pedro -Teixeiras, Minas Gerais.

\section{A GEOGRAFIA DAS RELIGIÕES: APROXIMAÇÕES TEÓRICAS}

A Igreja Católica, com viés Progressista, visa entender a instituição católica que desenvolve práticas com as classes sociais com o intuito de focar a radicalização da realidade, implantando uma sociedade mais igualitária. Essa, quando atrelada aos movimentos sociais e à igreja católica progressista, tem muito a oferecer, pois exerce tamanha influência em diversos aspectos. Mesmo o Brasil sendo um país laico, o catolicismo tem seus valores sobressaídos e, quando os movimentos são apoiados pelo mesmo, pode-se afirmar uma vantagem em comparação a outros movimentos.

Em adaptações junto à teologia da libertação, os princípios das duas unem forças, conquistando discípulos e grandes líderes religiosos e comunitários. Na Zona da Mata Mineira, essa união entre o catolicismo progressista e os movimentos sociais fica caracterizada como ação coletiva, junto a movimentos como o dos Atingidos por Barragens, em que alguns seguidores da religião se identificavam como atingidos por uma injustiça ambiental, porém não poderiam falar pela instituição levando em consideração a hierarquia dentro da religião. A Igreja Católica se posicionou a favor do movimento dos atingidos, mesmo que este posicionamento seja fruto de toda 
uma reformulação, principalmente, da Arquidiocese de Mariana, especificamente no ano de 1988, com Dom Luciano adepto à teologia da libertação e assumiu como bispo, unindo ainda mais os movimentos e sendo um dos grandes líderes da Ação Coletiva.

Dessa forma, a Igreja se torna o ponto de diálogo entre os movimentos e os fiéis, agregando valores e confiança às lutas. A Teologia da libertação tem como princípio a liberdade, contrapondose à opressão, utilizando-se da combinação de conceitos das ciências sociais com as ideias bíblicas e teológicas. Ela surge com diversas vertentes, como a teologia da libertação negra, a teologia da libertação latino-americana, a teologia da libertação feminista e, dessa forma, aborda os princípios do Livro de Êxodo, escrita na qual a luta por direitos ocupa um ponto principal unindo a fé com política.

Encarado do ponto de vista do próprio processo de libertação, o Livro do Êxodo identificava dois momentos: libertação da opressão do faraó e libertação para a Terra Prometida. É esse paradigma que orientava grande parte desta Teologia da Libertação. (OUTHWAITE; BOTTOMORE, 1996, p. 762).

Em 1970 as ideias da Teologia da libertação tomaram espaço e ênfase nas atuações sociais e políticas, dando espaço para tornar a luta social mais justa no Brasil. Junto à CEBs (Comunidades Eclesiais de Base) mobilizou um número significativo de articulações populares, destacando a importância na formação do Partido dos Trabalhadores (PT), afirma Rachel Meguelo (1989)

A aproximação da Igreja ao partido deu-se desde o início, e foi provavelmente estimulada pela ideia existente da Igreja de viabilizar a construção de um partido dos trabalhadores, "um PT cristão". Esta ideia, sem dúvida, refletia a orientação progressista que setores da CNBB (Conferência Nacional dos Bispos do Brasil) esboçavam, fundamentada na 'Teologia da Libertação (RACHEL MEGUELO,1989, p. 64).

Porém quando reunida a fé com a política, movimentos se unem por um bem maior. Um exemplo é o Movimento dos Atingidos por Barragens, pois algumas de suas sedes e mobilizações se juntam às igrejas católicas com vertentes da teologia da libertação para irem contra desastres ambientais causados por ações irregulares de mineradoras, como os desastres de Mariana, de Brumadinho e Congonhas, onde certas classes sociais foram atingidas e silenciadas. Assim, por meio da fé e de políticas sociais, o diálogo para a luta por direitos das comunidades ganhou força e apoio para lutar por uma sociedade mais justa.

Segundo Oliveira (2005 e 2010) o Movimento da Boa Nova (Mobon) é a prática concreta da ação coletiva entre os movimentos sociais e a religião. O Mobon, sendo um movimento católico junto a movimentos sociais, desenvolveu concepções políticas entre grupos e comunidades rurais e sindicais. Formado em 1960, em Minas Gerais (com destaque na Zona da Mata, Vale do Rio Doce e Região Leste), tem como princípio a educação religiosa e a evangelização, formando leigos 
católicos em lideranças comunitárias que passassem as ideias religiosas às comunidades de forma dinâmica reproduzindo assim o ideal católico. Essas lideranças, depois de suas formações, chegam a patamares na política e em outras instâncias coletivas representativas, colocando sempre em destaque o fator em que fazer política cristã e de libertação é colocar o lado religioso para a tomada de decisão nas práticas políticas e sociais. De acordo com Teixeira (2020) o Mobon chegou a promover mudanças em comportamentos de integrantes que, muitas vezes, não consideravam política e assim tiveram uma reformulação nas ideias, aceitando a política e se entregando até cargos de renome.

\section{MATERIAIS E MÉTODOS}

O município de Teixeiras localiza-se no Estado de Minas Gerais, na mesorregião Zona da Mata no sudeste do estado e abrange uma área 6,0\% do estado, possui uma população estimada de 11.661 habitantes sendo aproximadamente 40,0\% da população moradores e produtores rurais (IBGE, 2010), está a uma distância de 204 km de Belo Horizonte e faz divisa com Viçosa, Pedra do Anta e São Miguel do Anta (Figura 1) e apresenta uma economia baseada na agricultura.

Figura 1 - Polígono representando a área exata da comunidade de São Pedro
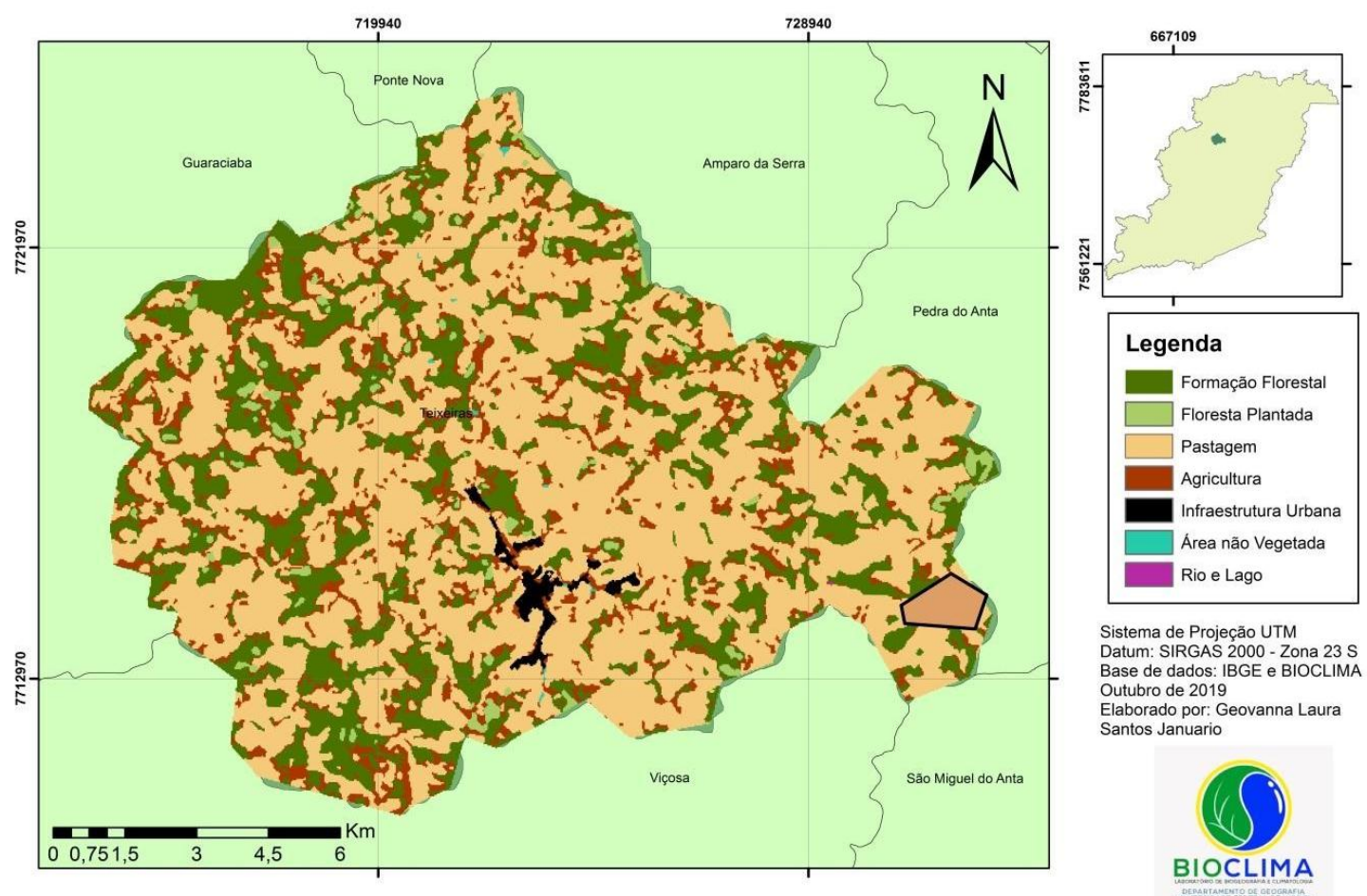

Organizado por: Geovanna Laura Santos Januário. 2019. 
Em relação à ocupação, a mesma reside em sua maioria nas porções mais planas, que correspondem as várzeas e baixas vertentes do Ribeirão Teixeiras e seus afluentes, onde a malha urbana está inserida (ROCHA; FIALHO, 2010). A comunidade de São Pedro, local são desenvolvidas as atividades da mineradora ZMM (Zona da Mata Mineração), se localiza na porção oeste do município, nas proximidades da divisa com Viçosa, Pedra do Anta e São Miguel do Anta (Figura 1), onde apresenta uma morfologia predominantemente ondulada, intercalada por áreas montanhosas em todas as direções, com altitudes variando a 600 a 929 metros (FIALHO, 2012).

Para obter uma primeira aproximação dos problemas, buscou caracterizar a área de estudo, contextualizando-a. Em seguida procurou levantar imagens de satélite antes e depois do início da atividade mineradora, no município de Teixeiras, por meio da plataforma do Land Viewer. Para caracterizar o uso e cobertura da terra, utilizou-se a base de dados do projeto de mapeamento anual da cobertura e uso do solo do Brasil (MapBioma), uma iniciativa colaborativa entre pesquisadores de diversas áreas, iniciada no ano de 2015 (MAPBIOMA, 2020), que utiliza a plataforma Google Earth Engine ${ }^{3}$, local de acesso a base de dados da coleção 5.0 (1985-2019), a partir dos scripts disponibilizados na plataforma por meio do link: https://code.earthengine.google.com/

Além disso, a pesquisa também se utilizou do método da observação participante, que conforme Given (2008) é um procedimento de coleta de dados, que consiste na participação do pesquisador nas atividades cotidianas relacionadas a uma área da vida social, a fim de estudar aspectos de vida por meio da observação de eventos em seus contextos naturais.

A abordagem está na interação cotidiana envolvendo conversas para descobrir as interpretações dos participantes nas situações que estão envolvidos. Segundo Marco e Elsen (2000), o método é especialmente adequado para o estudo de fenômenos sociais sobre o qual pouco se conhece. Nesse contexto, os momentos elencados para o desenvolvimento e coleta de informações e dados para a pesquisa foram cronologicamente:

a) Primeira Assembleia Popular, realizada no Centro Pastoral da Igreja Matriz de Santo, no dia 27 de abril de 2019.

b) A oitava edição dos festejos em homenagem a Nossa Senhora Aparecida, no dia 26 de agosto de 2019, na comunidade do São Pedro.

c) Segunda Assembleia Popular, com a organização de uma mesa de debates constituída por líderes religiosos, advogado, representantes da comunidade e da universidade, no dia 7 de marco de 2020.

\footnotetext{
${ }^{3}$ O Google Earth Engine (GEE) é uma plataforma utilizada em ampla escala com o objetivo principal de analisar dados ambientais. Uma das grandes vantagens dessa plataforma é o fato dela reunir mais de 40 anos de imagens globais de satélites, de décadas anteriores e atuais (GORELICK et al., 2017).
} 


\section{DISCUSSÕES E RESULTADOS}

Conforme informações do Estudo do Impacto Ambiental da empresa Zona da Mata Mineração a microrregião da Mata de Viçosa localiza-se é formada por um conjunto de 20 municípios: Alto Rio Doce, Amparo da Serra, Araponga, Brás Pires, Cajuri, Paula Cândido, Pedra do Anta, Piranga, Porto Firme, Presidente Bernardes, Rio Espera, São Miguel do Anta, Senhora de Oliveira, Teixeiras e Viçosa que se torna grande centro econômico devido a presença da Universidade Federal de Viçosa.

Como se trata de uma área com ocupações antrópicas seu domínio já não se encontra com vegetação originária da Mata Atlântica, sendo composta por campos diversos, eucaliptos, reflorestamentos secundários e plantios de café, milho e banana. Os ambientes antropizados apresentam espécies como capim braquiária (Urochloa decumbens), capim braquiária (Panicum maximum) e capim batatias (Paspalum notatum), das espécies arbóreas se tem destaque para canela sassafrás (Ocotea odorifera), jacarandá caviúna (Dalbergia nigra), espécies ameaçadas de extinção (Portaria MMA, 443/2014) e o Handroanthus chrysotrichus (Ipê amarelo) e protegida imune de corte no estado de Minas Gerais, de acordo com a Lei Estadual № 20.308, de 27 de julho de 2012.

A fauna local é composta por uma riqueza de aves, sendo uma característica da Mata Atlântica na região foram registrados, pelo estudo do impacto ambiental da empresa ZMM (Zona da Mata Mineração), 136 espécies de aves distribuídas em 21 ordens e 44 famílias. A avifauna registrada representa 17,0\% das espécies registradas para Minas Gerais (COPAM, 2010).

A extensão de monocultura, faz com a fauna seja prejudicada tendo grande número de animais criados para o auto sustento, como gado de pastagem e grande ocorrência de animais domésticos. Apesar da ação antrópica se de grande escala suas alterações na flora do local não são intensas na proporção da ação da mineradora no local, e suas alterações na fauna causa uma homogeneidade entre as espécies, mas também não na proporção em que o impacto da ação minerária causa.

A área de estudo a ser analisada consiste nas instalações da empresa de mineração Zona da Mata Mineração S.A, na localidade da divisa entre Pedra do Anta, São Miguel do Anta e Teixeiras, municípios da Zona da Mata Mineira, afetando indiretamente os fluxos transitórios do município de Viçosa (Figura 2).

Especificamente nas localidades da comunidade de São Pedro, a empresa Zona da Mata Mineração S.A está em processo de implantação de operações dentro da localidade, porém diversos conflitos com a população estão se perpetuando. Desde 2018 o processo sem diálogo com a população é um dos fatores principais de discussão. Com a finalidade de expor os processos 
conflituosos, a pesquisa acompanhou os movimentos sociais e mobilizações frente às preocupações sociais e ambientais, na comunidade rural de São Pedro, o racismo ambiental analisado também está relacionado a classe de baixa renda camponesa, que sofre não mais com um racismo voltado somente à raça, mas também ao preconceito e discriminação às tradições ambientais onde estão inseridas.

Figura 2. Mapa de uso e caracterização do solo das áreas afetadas. Municípios de Viçosa, Teixeira, Pedra do Anta e São Miguel do Anta

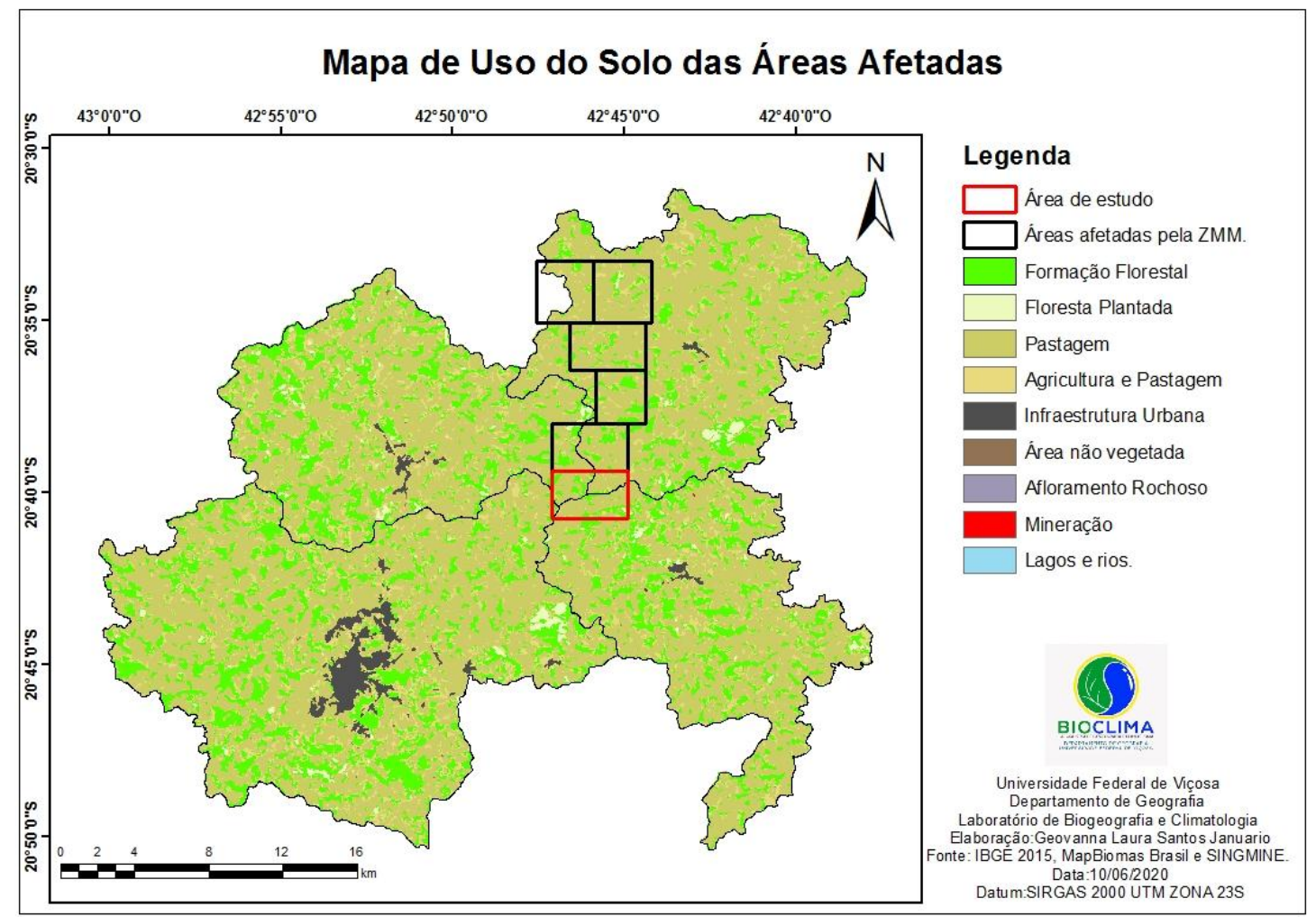

Organizado por: Geovanna Laura Santos Januário. 2020

Na Figura 3, é possível observar a comparação na comunidade antes e depois do processo de implantação e início de exploração mineraria da empresa, com uma mudança significativa no volume de vegetação, gerando consequências para a fauna e para a economia local, como contribuindo para o aumento da temperatura da superfície, que em função da atividade mineradora, que promove a retirada da cobertura vegetal, e, por conseguinte de parte do solo em superfície, deixando exposto o solo. A consequência disto é o aumento da temperatura de superfície, como pode ser visualizado no trabalho de Santos e Fialho (2020, p. 11). Além disso, a superfície ao ficar sem proteção de uma cobertura fica vulnerável às chuvas, que apresentaram dificuldades para infiltrarem, acarretando um aumento do escoamento superficial, que será carreado até um córrego mais próximo, possivelmente, aumentando sua turbidez. Muito embora, nas tratativas de concessão 
da lavra, a empresa se comprometa em regenerar a área, o fato em questão, que durante a exploração, não há como evitar o carreamento de sedimentos em direção aos canais fluviais.

Figura 3 - Vista aérea da comunidade de São Pedro antes e depois da instalação da mineradora. Primeira imagem referente a 13/07/2019 segunda imagem 30/09/2020
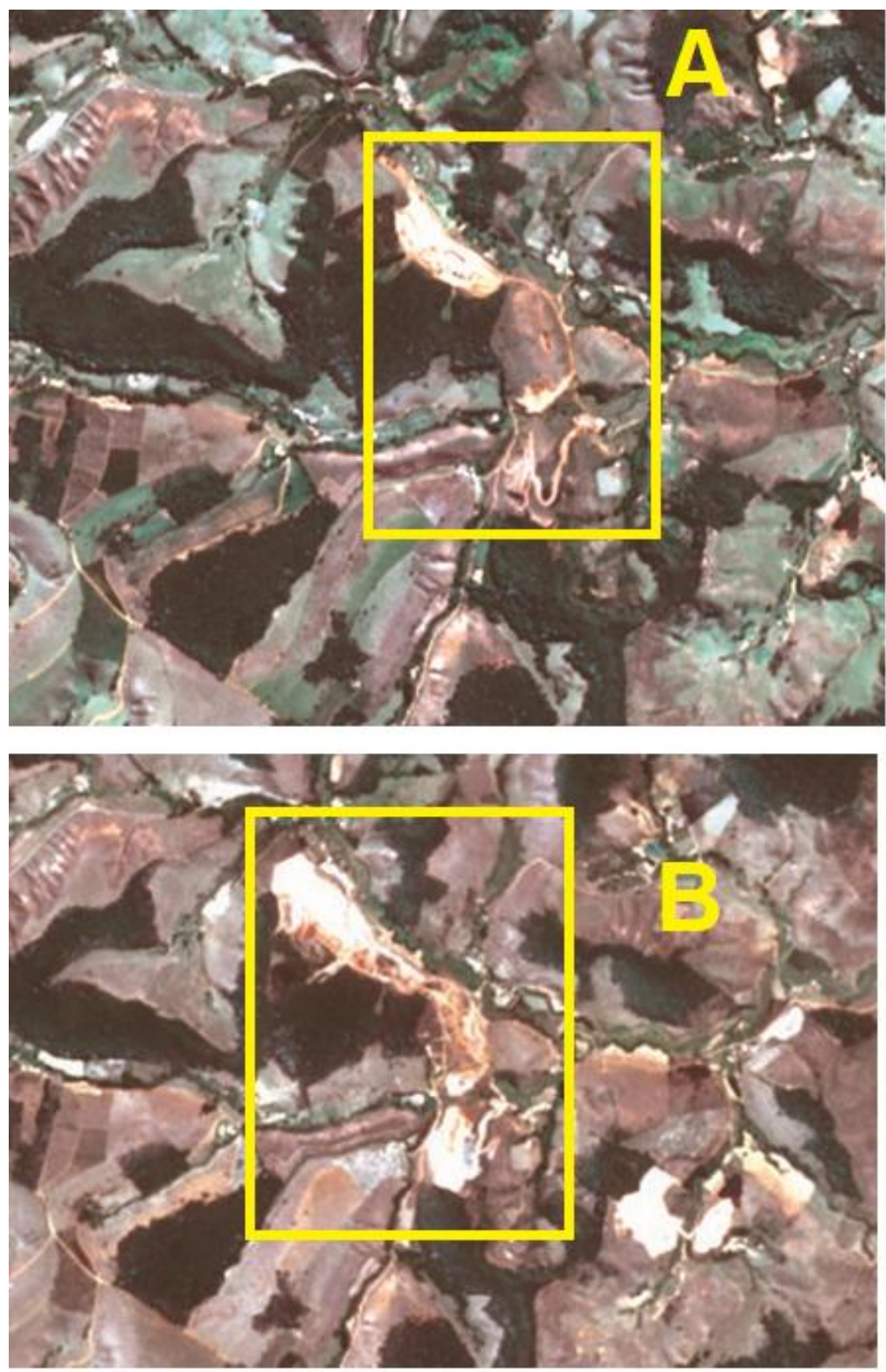

Fonte: Landviewer. Disponível em: https://eos.com/landviewer/?lat=-20.73530\&lng=-42.89530\&z=11 Organizado por: Geovanna Laura Santos Januário. 2020.

Uma outra questão relacionada aos impactos, apesar da vantagem empregada na mineração a seco desenvolvida, que evita a criação de barragens de rejeito, como explanado por Nascimento et al. (2020) e muito divulgado pela empresa ZMM, se relaciona o escoamento da produção minerária, que se utiliza de caminhões de grande porte, que apesar de utilizarem em grande parte rodovias rurais, em dias de chuva, quando o percurso se torna inviável, os caminhões passam 
obrigatoriamente dentro da cidade, onde de as ruas não foram planejadas para o tamanho de carga mobilizado pelos caminhões, que é constante, uma vez, que a empresa mineradora não para, a mesma funciona 24 horas em três turnos.

\subsection{RELATOS DE UMA PRIMEIRA APROXIMAÇÃO: PRIMEIRA ASSEMBLEIA POPULAR}

Nesse contexto, no dia 27 de abril de 2019, foi organizado por entidades do movimento social, como MAM (Movimento dos Atingidos pela Mineração); MAB (Movimento de atingido por Barragens); AGB-Viçosa (Associação de Geógrafos do Brasil); Levante Popular da Juventude e o MST (Movimento dos sem-terra), uma Assembleia Popular (Figura 4), realizada na quadra da Capela do Nosso Senhor do Bom Jesus, a fim de expor os problemas que a mineração poderá trazer, bem como comunicar os meios pelos quais a mesma está atuando, através da promoção da discórdia entre os membros da comunidade, que agora tem conflitos declarados pelo desencontro de informações.

Figura 4 - Assembleia Popular, realizada no Centro Pastoral da Igreja Matriz de Santo Antônio, no dia 27 de abril de 2019.

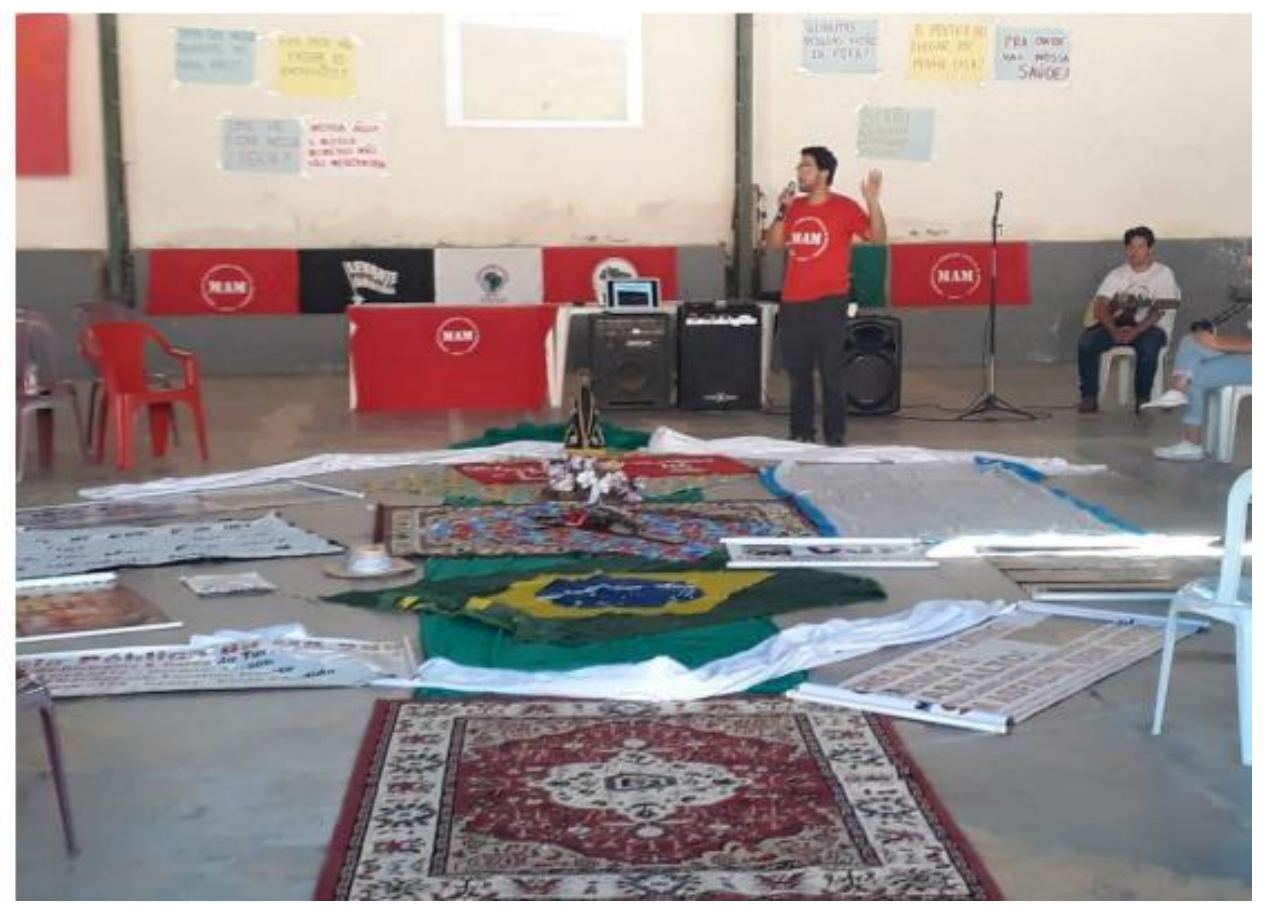

Fotografia: Edson Soares Fialho (2019).

De acordo com os organizadores da assembleia (BRASIL DE FATO, 2019), a empresa estaria violando direitos humanos e ambientais no processo de chegada na comunidade, não informando a população sobre os reais impactos e as iniciativas para resolve-los, além de não 
reconhecerem várias famílias como atingidas. A assembleia reuniu aproximadamente 200 pessoas, mas não apenas moradores de Teixeiras, mas de outras cidades, que também passam pelos mesmos problemas relacionados a mineração. Acompanhando as falas dos presentes, verificou-se uma grande preocupação dos moradores, em função da falta de informação sobre os impactos que podem advir do empreendimento, principalmente, relacionada aos corpos hídricos.

Apesar da Assembleia ter o intuito de informar e mobilizar a população atingida, cabe destacar, que a ZMM não foi convidada neste momento para participar desta atividade, porém, mesmo assim, a empresa utilizou-se do artifício de distribuir um folheto informativo, logo na entrada do Centro Pastoral, causando certo desconforto e desconfiança entre os participantes da assembleia e os próprios moradores dos arredores do Centro Pastoral, que se preocuparam com o aumento de possível tensão entre as partes.

\subsection{OITAVA CAMINHADA DE NOSSA SENHORA APARECIDA}

No dia 26 de agosto de 2019, ocorreu no município de São Pedro a $8^{\circ}$ Festa de Comunidade Nossa Senhora Aparecida. O município nesses últimos meses anda em conflito com a empresa Zona da Mata Mineira, mineradora que abrigou suas instalações em regiões não regulamentadas e que prejudicam a população local. Os movimentos de resistência à mineradora surgem de todos os lados nas localidades, partindo de auxílios de professores e técnicos da Universidade Federal de Viçosa à potências influenciadoras da comunidade, como as forças religiosas.

No dia 25 de agosto, houve alguns encontros entre as comunidades pastorais e movimentos na casa do Sr. João Coutinho, localizada no terreno abaixo das instalações da mineradora e diretamente afetada por suas consequências. Assim, dentre as manifestações religiosas presentes, pôde-se perceber o posicionamento negativo frente às ações da ZMM, orando sempre para Nossa Senhora Aparecida pelo o fim das atividades e pela proteção de todos os que seriam atingidos diretamente ou indiretamente.

Durante o encontro houve uma mística na qual os representantes leram o Gênesis e o Antigênesis quando foram citados pontos que mostram a importância da luta contra a exploração da mineradora por envolver ações humanas que afetam um espaço socioambiental, transformando o que seria a casa erigida por Deus em um espaço de domínio da força e violência e imperfeições do homem.

Após algumas manifestações de representantes da região, iniciou-se uma caminhada (Figura 5) em direção à casa do Sr. João Maroca e o caminho percorrido passou ao lado dos terrenos afetados pela mineração e em constante transformação devido às atividades. Durante a expedição a 
mineradora se encontrava parada em virtude do dia da semana e também da ação de uma liminar contra as atividades da mesma, já em vigência por falta de regulamentações e por motivos de que afetariam a comunidade local.

Durante todo o caminho, as pregações para que os atos da mineradora parassem estiveram presentes e a comunidade religiosa sempre tiveram um posicionamento claro e resistente, a favor da luta social e igualitária.

Figura 5 - Caminhada de Nossa Senhora Aparecida nas áreas da Mineradora - Comunidade de São Pedro, município de Teixeiras - MG, no dia 26 de Agosto de 2019.

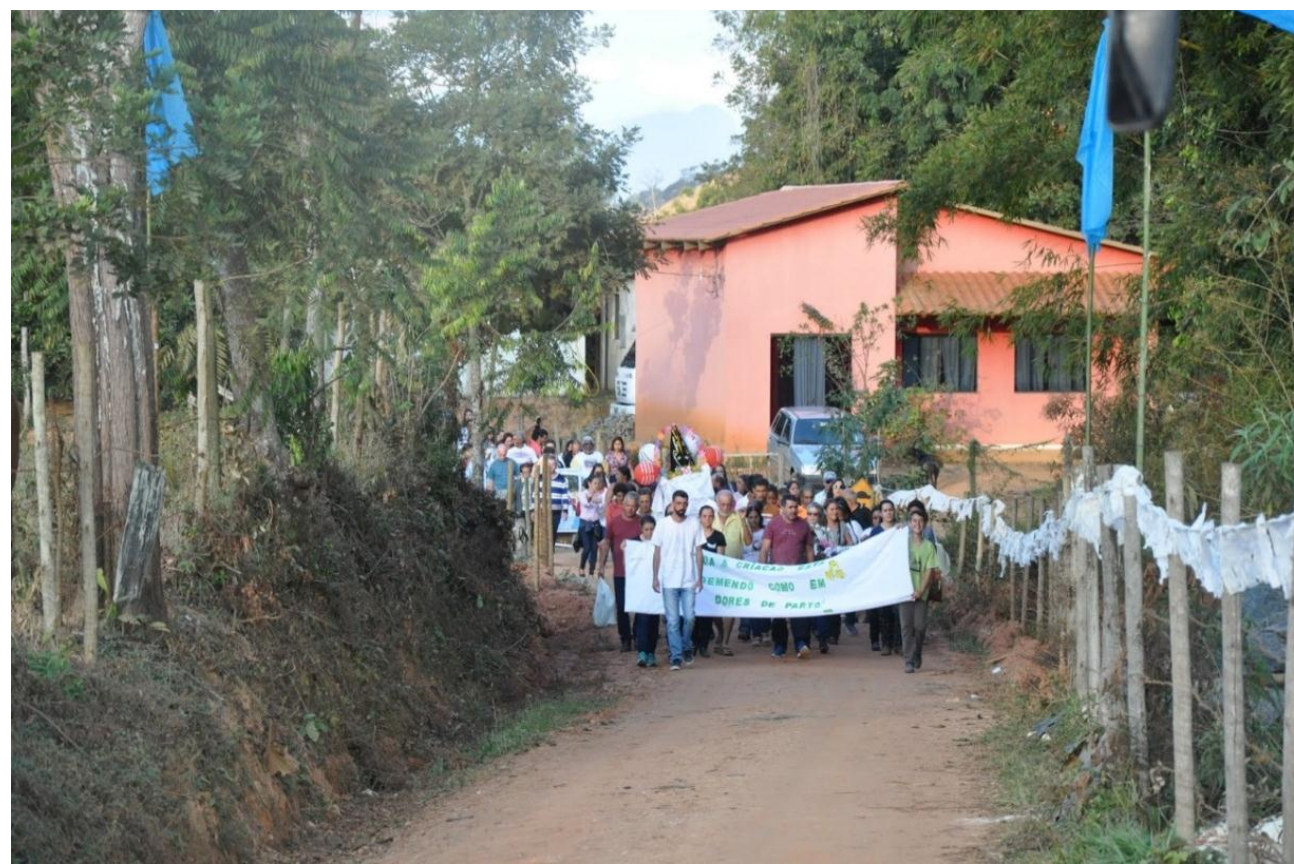

Fotografia: Edson Soares Fialho (2019).

\subsection{RELATOS DE UMA SEGUNDA APROXIMAÇÃO: $2^{\mathrm{A}}$ ASSEMBLEIA POPULAR CONTRA A MINERADORA - IMPACTOS CAUSADOS}

Em 7 de março 2020, uma segunda assembleia popular foi convocada pelo MAM com todos os representantes e moradores dos municípios afetados pela constante atividade da mineradora ZMM, debatendo sobre os impactos e suas consequências as comunidades. A mesa de debate planejada para conter representantes, com opiniões técnicas e sociais sobre os impactos.

A mesa foi composta pelo padre Geraldo, José Ignácio Esperança Fonseca, assessor jurídico do NACAB (Núcleo de Assessoria às Comunidades Atingidas por Barragens), a professora Marilda Teles Maracci do Departamento de Geografia da UFV, Jean Carlos Martins Silva (Representante do MAM), Rita de Cássia Dias e Gilmar Fialho de Freitas (Representantes da comunidade). Mas, apesar dos representantes da ZMM não participarem da mesa, a empresa utilizou uma estratégia de 
pressão, mobilizando seus funcionários a participarem do evento, distribuindo panfletos e segurando cartazes, que colocavam a questão do emprego e renda com cruciais para o desenvolvimento e manutenção de suas famílias. Esta questão, muito importante, não pode ser analisada de maneira simplista, colocando a empresa como o centro da possibilidade de melhoria de vida dos seus empregados. A questão não pode ser colocada desta maneira, pois, como o padre Geraldo Martins, destacou em sua fala, o que está em jogo é preservação da vida em todas as suas dimensões.

Nesse sentido, segundo a fala do padre Geraldo, a Igreja deve participar, pois a:

A Igreja não tem uma palavra técnica em relação a mineração, ela se firma nos princípios da Doutrina Social da Igreja: a defesa da vida, da dignidade humana, da ética, da justiça. A reflexão da Igreja é para avaliar até que ponto essa atividade econômica respeita esses princípios. Porque, a medida que qualquer atividade humana, sobretudo uma atividade econômica, falta ou agride alguns desses princípios, ela precisa ser revista. (ARQUIDIOCESE DE MARIANA, 2020).

E assim, o presbítero finalizou sua participação colocando a questão: Não é se deve ter ou não mineração, mas qual mineração deve ser feita? Quais são de fato os impactos que a mineração provoca na comunidade, no meio ambiente, na vida das pessoas? Por isso, a Igreja participa, sem medo de dizer, sempre ao lado dos mais vulneráveis.

Após as falas da mesa, os participantes da assembleia tiveram a oportunidade de participar da fila do povo (Figura 6), que registrou manifestação da plateia que lotou o Centro Pastoral, que tinha as suas 400 cadeiras ocupadas, mas a arquibancada, que continha aproximadamente 200 pessoas, totalizando 600 indivíduos.

Em seguida, a fala foi aberta ao público para realização de questões ou manifestações públicas. Como havia um grande número de funcionários da empresa mineradora, algumas falas acaloradas dos mesmos causaram desconfortos e princípios de tumultos, chegando a insultos direcionados aos membros da mesa, que colocavam sua posição, que desagrava aos ouvintes.

Assim como sempre relatada, a presença de líderes religiosos, como do Padre Geraldo à mesa e sua opinião para o consenso da população foi essencial, tanto para demonstrar o posicionamento das entidades religiosas representadas frente aos impactos causados pela mineração, quanto para acalmar os insultos por parte dos defensores da atividade mineral contra a população e técnicos. 
Figura 6. Segunda Assembleia popular e mesa de debates constituída por líderes religiosos e profissionais. Local: Centro pastoral da Igreja Matriz de Santo Antônio, 7 de março de 2020.

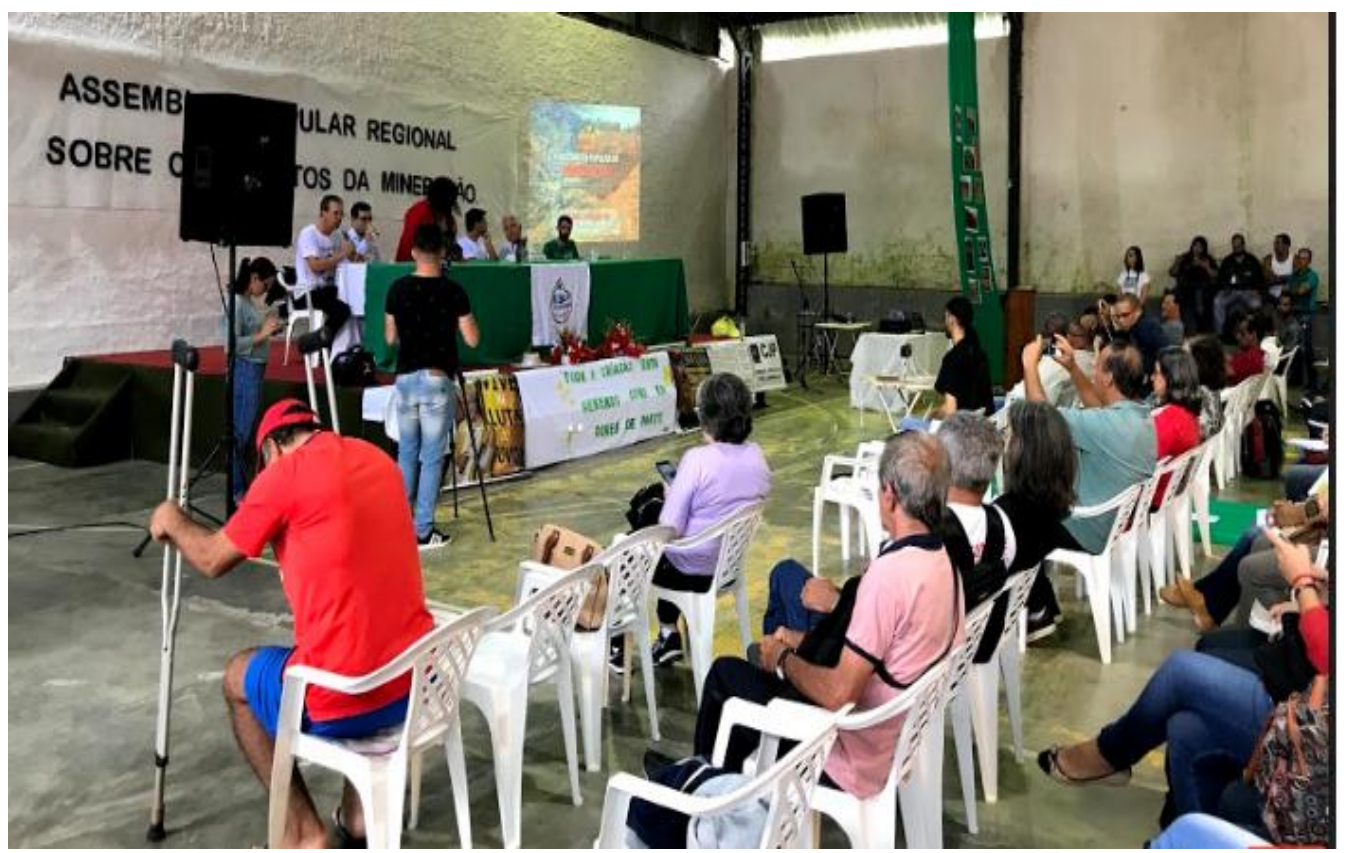

Fotografia: Geovanna Laura Santos Januário. (2020).

A religiosidade naquele momento foi o fator que mais atraiu, ambos os lados na assembleia, pois o respeito a entidades e representações "superiores" faz com que os lados opostos se encontrem em algum momento no fator cultural e, como sempre reafirmada, o posicionamento do representante religioso local, os impactos e consequências da mineradora para a comunidade foram bem enaltecidos.

\subsection{O RACISMO AMBIENTAL E AS APROXIMAÇÕES RELIGIOSAS}

O processo de implementação da mineradora na região passou a ser um processo ríspido e com diversas imposições frente a acidentes resultados da exploração territorial, o auxílio da Universidade Federal de Viçosa sobre os estudos dos impactos ambientais com profissionais qualificados orientou a comunidade junto a forças de colaboradores e entidades como arquidioceses e igrejas criaram um movimento de resistência e contraposição ao modelo mineral, mesmo que a seco, implantado na região.

O preconceito e a superioridade impostos pela empresa mineral ZMM, a forte presença de poeira nas dependências das moradias, a perseguição a famílias e líderes que se posicionam contra a mineradora, o impacto dos caminhões e meios de transportes nas vias de acesso ao município, o impacto causado nas áreas de fontes hídricas, e principalmente a exploração territorial em uma 
comunidade tradicional são evidencias de um racismo, injustiça e negligência ambiental. Tal fato corrobora a posição de racismo ambiental.

Segundo Herculano (s/d) a expressão surgiu no campo de debates e de estudos sobre justiça ambiental, um clamor inicial do movimento negro estadunidense e que se tornou um programa de ação do governo federal dos Estados Unidos, por meio da EPA (Environmental Protection Agency), sua agência federal de proteção ambiental. O conceito diz respeito às injustiças sociais e ambientais que recaem de forma desproporcional sobre etnias vulnerabilizadas.

Tal observação é corroborada por Silva (2012) que verifica que existência de situações de injustiça ambiental, significa que, em sociedades desiguais, os grupos racialmente discriminados e as populações de baixa renda (grupos vulneráveis e marginalizados) são os que arcam com a carga mais pesada dos danos ambientais gerados pelo desenvolvimento. Retratando a teoria que o racismo ambiental e a justiça ambiental não se baseiam no preconceito e repulsa simplesmente a cor de pele sim perpassa pela cultura e maneira de vida, e desrespeito territorial. $\mathrm{O}$ apoio a resistências e as formas de luta providos dos movimentos religiosos da região é uma forma de combate ao racismo ambiental, dessa forma a relação da população junto aos enfrentamentos torna se sempre presente, e com apoios cada vez maiores conforme suas vivencias.

\section{CONSIDERAÇÕES FINAIS}

A partir das primeiras sondagens, observa-se, no atual estágio da pesquisa, que durante um longo do tempo a religiosidade resistiu em se posicionar a favor das lutas sociais ou em prol de movimentos políticos, porém houve adaptações e mudanças que promoveram a união dos dois tendo como foco a luta por uma sociedade igualitária e justa. As religiões, independentes de sua origem, procuram trabalhar frente às injustiças ambientais cujo o discurso formador é o qual vai orientar suas ações. A pesquisa traz uma perspectiva mais cristã e do catolicismo, mas não anula em momento algum as vertentes de religiões de matrizes africanas e indígenas, altamente presentes nas lutas dos movimentos sociais, principalmente por terem como força maior a natureza.

O trabalho em campo da área de estudo em questão (Comunidade do São Pedro), ainda não se encontra finalizado, mas há que se destacar que a presença de movimentos sociais e da religião estão unidos contra um ato de uma mineradora, desde o início de suas atividades. A comunidade luta por direito a terras e contra qualquer ato irregular nas terras locais, o que poderia ser considerado crime ambiental. 


\section{REFERÊNCIAS}

ARQUIDIOCESE DE MARIANA. Impactos da Mineração são debatidos em Assembleia Popular em Teixeiras. Minas Gerais, 10 de março de 2020. Disponível em: https://arqmariana.com.br/noticia/impactos-da-mineracao-sao-debatidos-em-assembleia-popularem-teixeiras/. Acesso em: 2 jan. 2020.

BRASIL DE FATO. Mais de 200 pessoas participam da Assembleia Popular da Mineração em Teixeiras (MG). Minas Gerais, 30 de abril de 2019. Disponível em: https:// www.brasildefatomg.com.br/2019/04/30/mais-de-200-pessoas-participam-da-assembleia-popularda-mineracao-em-teixeiras-mg. Acesso em: 3 jan. 2020.

CLAVAL, P. La Theme de la Religion dans les Études graphiques. Géographie et Cultures, ParisFRA, n. 2, p. 85-111, 1992. Disponível em: https://journals.openedition.org/gc/3501. Acesso em: 17 nov. 2020.

COSTA OLIVEIRA, F. R.; ZANGELMI, A. J. O Mobon, a política e a imprensa: notas sobre religião e política em Minas Gerais. Horizonte, Belo Horizonte-MG, v. 7, ed. 14, p. 170-186, 2009. Disponível em: http://periodicos.pucminas.br/index.php/horizonte/article/view/P.2175-5841.2009v7n14p170. Acesso em 22 nov. 2020.

COPAM. Lista de Espécies Ameaçadas de Extinção da Fauna do Estado de Minas Gerais. DELIBERAÇÃO NORMATIVA COPAM No 147, DE 30 DE ABRIL DE 2010 Disponível em: http://www.siam.mg.gov.br/sla/download.pdf?idNorma=13192. Acesso em: 4 jan. 2020.

FIALHO, E. S. O meio ambiente: o discurso geográfico rumo a transdisciplinaridade. Revista Ponto de Vista, Viçosa - MG, v. 4, p. 39-48, 2007. Disponível em: https://www.locus.ufv.br/bitstream/ 123456789/21171/1/artigo.pdf. Acesso em: 30 nov. 2020.

FIALHO, E. S. Estudos climáticos em sítios urbanos e rurais. In: FIALHO, E. S.; SILVA, C. A. (Org.). Concepções e Ensaios da Climatologia Geográfica. Dourados-MS: UFGD, 2012, v. 1, pp. 83-114. Disponível em: https://www.researchgate.net/publication/327890815_ESTUDOS_CLIMATICOS_ EM_SITIOS_URBANOS_E_RURAIS. Acesso em: 24 nov. 2020.

FONSECA, B. C.; OLIVEIRA, M. L.; SOUSA, D. R. Conflitos ambientais: atores, causas e desdobramentos na zona da mata mineira. Caminhos da Geografia, Uberlândia-MG, v. 13, n. 42, p. 283-299, 2012. Disponível em: http://www.seer.ufu.br/index.php/caminhosdegeografia/article/view/16743. Acesso em: 23 nov. 2020.

FONSECA, B. C.; FIÚZA, A. L. C. Ação coletiva e mediação religiosa o campo no brasil: evidências históricas na arquidiocese de Mariana-Minas Gerais. Revisita HOLOS, Natal-RN, v. 3, p. 371-392, 2015. Disponível em: http://www2.ifrn.edu.br/ojs/index.php/HOLOS/article/view/2694. Acesso em: 3 jan. 2021

GIL FILHO, S. F. Por uma Geografia do Sagrado. In: MENDONÇA, F.; KOZEL, S. (orgs.). Elementos de epistemologia da geografia contemporânea. 2. Ed. Curitiba: Editora UFPR, p. 253-265, 2004. 265p.

GIVEN, L. M. The Sage encyclopedia of qualitative research methods, v.1. California: SAGE Publications, 2008.

GOOGLE EARTH ENGINE: Planetary-scale geospatial analysis for everyone. Remote Sensing of Environment, v. 202, p. 18-27, 2017. Disponível em: https:/www.sciencedirect.com/ science/article/pii/S0034425717302900. Acesso em: 30 dez. 2020. 
Instituto Brasileiro de Geografia e Estatística (IBGE). Censo demográfico (2010). Disponível em: https://cidades.ibge.gov.br/brasil/es/venda-nova-do-imigrante/panorama. Acesso em: 4 jan. 2021.

HERCUlAnO, S. Racismo Ambiental, o que é isso? Disponível em: https://www. researchgate.net/profile/Selene_Herculano/publication/266344253_RACISMO_AMBIENTAL_O_ QUE_E_ISSO/links/543746640cf2643ab9889338/RACISMO-AMBIENTAL-O-QUE-E-ISSO.pdf. Acesso em: 4 jan. 2021.

LEVY, C. Influência e contribuição: a igreja católica progressista brasileira e o fórum social mundial. Religião e sociedade, Rio de Janeiro-RJ, v. 29, n. 2, p. 177-197, 2009. Disponível em: https://www.scielo.br/pdf/rs/v29n2/v29n2a09.pdf. Acesso em: 2 jan. 2021.

MAPBIOMAS - Projeto de Mapeamento Anual da Cobertura e Uso do Solo no Brasil. Coleção 4.0. Disponível em: http://mapbiomas.org/. Acesso em: 23 dez. 2020.

MARCON, S. S.; ELSEN, I. Estudo qualitativo utilizando observação participante - análise de uma experiência. Acta Scientiarum, Maringá-PR, v.22, n.2, p. 637-647, 2000.

NASCIMENTO, J. C. S.; NASCIMENTO, J. S. S.; RIBEIRO, P. S.; MELO, F. B. S.; SOUSA, L. M.; REIS, P. S. G.; SILVA, L. A. B.; CARVALHO, L. V. Mineração através do beneficiamento à seco em Canaã dos Carajás-PA: alternativa para a barragem de rejeitos. Brazilian Journal of Development, Curitiba-PR, v. 6, n. 10, p. 80788-80800, oct. 2020. Disponível em: https://www.brazilianjournals.com/index.php/BRJD/article/view/18652/15020. Acesso em 4 jan. 2020.

OLIVEIRA, F. R. C.; ZANGELMI, A. J. Religião, comunicação e cultura política: da vida religiosa e á luta pela cidadania. Revista de Ciências Humanas, Viçosa-MG, v. 9, n. 2, p. 216-228, 2009. Disponível em: https://periodicos.ufv.br/RCH/article/view/3506. Acesso em: 20 dez. 2020.

OLIVEIRA, F. R. C. Religião e mobilização social na arquidiocese de Mariana/MG. 2005. 174f. Dissertação (Mestrado em Extensão Rural) - Departamento de Economia Rural, Universidade Federal de Viçosa, Viçosa. 2005. Disponível em: https://www.locus.ufv.br/bitstream/123456789/9974/1/texto\%20completo.pdf. Acesso em: 25 nov. 2020.

OLIVEIRA, F. R. C. O Concílio Vaticano II, o Mobon e as comunidades rurais: um estudo sobre a práxis comunicativa entre missionários e grupos católicos leigos. Religião \& Sociedade, v. 30, n. 2 , p. 38-58, 2010. Disponível em: https://www.scielo.br/pdf/rs/v30n2/a03v30n2.pdf. Acesso em: 25 nov. 2020.

ROCHA, C. S.; FIALHO, E. S. Modelando a exceção: A cidade de Teixeiras-MG e a enchente de 1975. In: CONGRESSO BRASILEIRO DE ORGANIZAÇÃO DO ESPAÇO E SEMINÁRIO DE PÓS-GRADUAÇAO EM GEOGRAFIA DA UNESP - Rio Claro, 1 e 10, 2010, Rio Claro-SP. Anais..., São Paulo: Unesp-RC, 2010a. Disponível em: https://www researchgate.net/publication/273774399_MODELANDO_A_EXCECAO_A_CIDADE_DE_TEIXEIRAMG_E_A_ENCHENTE_DE_1975. Acesso em: 2 jan. 2020.

SANTOS, M. A natureza do espaço: técnica e tempo, razão e emoção. São Paulo: Edusp, 2009. 392p.

SANTOS, L. G. F.; FIALHO, E. S. Análise da distribuição da Temperatura de Superfície em relação ao Índice de Vegetação por Diferença Normalizada, em estação seca e chuvosa, no município de Teixeiras-MG. Revista Ponto de Vista, Viçosa-MG, v. 9, n. 3, p. 95-112, 2020. Disponível em: https://periodicos.ufv.br/RPV/article/view/10805. Acesso em: 2 jan. 2020.

SILVA, R. Geografia da religião: uma contribuição de abordagem através das práticas espaciais de intolerância religiosa na urbanidade carioca. Revista Acadêmica Magistro, Duque de Caxias-RJ, v. 1, n. 5, 2012. Disponível em: http://publicacoes.unigranrio.edu.br/index.php/magistro/article/view/1411. Acesso em: 12 set. 2020. 
SILVA, E. A Teologia da Libertação na América Latina: contexto histórico e teológico do surgimento. Revista Brasileira de História das Religiões, Maringá-PR, v. 5, n. 15, 2013. Disponível em: www.dhi.uem.br/gtreligiao/pub.html. Acesso em: 12 set. 2020.

SILVA, A. S.; GIL FILHO, S. F. Geografia da Religião a partir das formas simbólicas em Ernst Cassirer: Um Estudo da Igreja Internacional da Graça de Deus no Brasil. Revista de Estudos da Religião, São Paulo-SP, p. 73-91, 2009. Disponível em: https://www.pucsp.br/rever/ rv2_2009/t_silva.pdf. Acesso em 18 dez. 2020.

SILVA, L. H. P. Ambiente e justiça: sobre a utilidade do conceito de racismo ambiental no contexto brasileiro, E-cadernos CES, São Paulo-SP, v. 17, 2012, Disponível em: http://journals. openedition.org/eces/1123. Acesso em: 2 jan. 2020.

TEIXEIRA, R. S. Como a rama da abóbora: o Movimento da Boa Nova, o "trabalho de base" e (re)invenções de saberes-fazeres. 2020. 213 f. Dissertação (Mestrado em Antropologia Social) Programa de Pós-Graduação em Antropologia Social, Museu Nacional, Universidade do Rio de Janeiro, Rio de Janeiro. 2020.

ZHOURI, A.; ROTHMAN, F. D. Assessoria aos atingidos por barragens em Minas Gerais: desafios, limites e potencial, in: ROTHMAN, F. D. (Org.), Vidas alagadas: Conflitos socioambientais, licenciamento e barragens, Viçosa: UFV, p. 122-168, 2008. 344p. 